\title{
THE ANALYZE OF INFLUENCE MOTIVATION AND WORK SATISFACTION TO EMPLOYEES PERFORMANCE OF PT. INDOTECH METAL NUSANTARA KARAWANG
}

\author{
NENENG SOFIYANTI, DIAN HAKIP NURDIANSYAH DAN \\ ANGGI PASCA ARNU \\ Faculty of Economic and Business Singaperbangsa Karawang University
}

The result of preliminary studies was found that Employees Performance is not optimal. Motivation and work satisfactin is the most dominant factor of influence. The research of target is obtaining empiric evidence and finding clarity of phenomenon and also conclusion about the influence of motivation and work satisfaction to employees performance PT Indotech Metal Nusantara Karawang. Expected can giving something for development economic science especially; management development of institute, public service management, marketing management, human resource and generally of economic science. The method used is descriptive survey and explanatory survey. The sampling technique was used simple random sampling. Data analysis techniques is to expose each variable we, it used range scale. Data analysis technique used correlation analysis technique variables and Path Analysis Technique, to expose the influence of motivation and work satisfaction. The conclusion from the examination that Motivation at PT Indotech Metal Nusantara Karawang is good with total score 628,6. Work satisfaction at PT Indotech Metal Nusantara Karawang is good with total score 613,9. Employees performance at PT Indotech Metal Nusantara Karawang is good with total score 626,7. Influence directly motivation to employees performance of $31,25 \%$, while the indirect influence of $3,06 \%$. In total influences of motivation to employees performance at PT Indotech Metal Nusantara Karawang of $34,31 \%$. Influence directly work satisfaction to employees performance of $7,13 \%$, while the indirect influence of $3,06 \%$. In total influences of motivation to employees performance at PT Indotech Metal Nusantara Karawang of $10,19 \%$. Simultaneously influence motivation end work satisfaction to employees performance at PT Indotech Metal Nusantara Karawang of 44,50\%.

Keywords: Motivation, Work Satisfication, Employee Performance 


\section{PENDAHULUAN}

Berdirinya sebuah perusahaan sebagai organisasi profit adalah untuk melaksanakan bisnis yang akan memberikan laba sebagai tujuan operasional bagi pemiliknya, baik perseorangan, keluarga, maupun kelompok, termasuk juga yang diselenggarakan oleh Negara. Laba merupakan sumber penghasilan yang dibutuhkan untuk memenuhi kebutuhan hidup. Dengan semakin berkembangnya industrialisasi di Indonesia serta tingkat persaingan yang tinggi antar perusahaan maka dibutuhkan sumber daya manusia yang terampil dan berkualitas serta memiliki kinerja yang tinggi untuk meraih laba kompetitif secara berkelanjutan. Sumber daya manusia yang berkualitas tersebut merupakan modal penting bagi perusahaan dalam menentukan strategi perusahaan mulai dari perencanaan sampai pengawasan sehingga tujuan perusahaan dapat dicapai dengan optimal.

Kondisi persaingan usaha yang semakin ketat membuat perusahaan berupaya mencari jalan bagaimana mengatasi dan memenangkan persaingan serta agar tidak memburuk dan bangkrut, diantaranya membuat kebijakan ketenagakerjaan yang mendukung tujuan perusahaan seperti merekrut karyawan sesuai dengan tuntutan pekerjaan. Kinerja merupakan implementasi dari rencana yang telah disusun tersebut. Kinerja merupakan hasil pekerjaan yang mempunyai hubungan kuat dengan tujuan strategis organisasi, kepuasan konsumen dan memberikan kontribusi ekonomi.

Hasil kerja atau prestasi merupakan gabungan dari tiga faktor terdiri dari minat dalam bekerja, penerimaan delegasi tugas, dan tingkat motivasi seorang pekerja, dapat dijelaskan juga bahwa kepuasan kerja pegawai akan mendorong pegawai mencapai kinerja yang tinggi.

PT Indotech Metal Nusantara Karawang, sejak awal berdirinya perusahaan salah satu tujuannya adalah mampu bertahan dengan menghasilkan kemampulabaan. Sehingga faktor-faktor yang dapat menjadi pendukung tercapainya tujuan perusahaan menjadi perhatian besar bagi perusahaan, salah satunya adalah keberadaan sumber daya manusia beserta hal-hal yang mampu meningkatkan kinerja perusahaan. motivasi dan kepuasan kerja karyawan adalah diantaranya. Maka untuk meningkatkan kualitas kerja karyawan idealnya dengan memberikan motivasi secara terus menerus kepada mereka.

Adanya ketidak sesuaian promosi dengan prestasi kerja karyawan menimbulkan ketidak percayaan dan ketidakpuasan terhadap atasan bahkan sampai ke tingkat pemilik perusahaan. dan motivasi yang rendah ketika di beri pekerjaan tambahan sehingga hal ini dapat memicu terjadinya penurunan kinerja karyawan yang pada akhirnya dapat menurunkan kapasitas produksi

Berdasarkan uraian di atas ,maka penulis tertarik untuk memilih, membahas masalah motivasi, kepuasan kerja yang ada diperusahaan pada saat ini, serta pengaruhnya terhadap kinerja karyawan secara umum.

\section{TINJAUAN PUSTAKA}

Manajemen adalah ilmu dan seni mengatur proses pemanfaatan sumber daya manusia dan sumber-sumber daya lainnya secara efektif dan efisien untuk mencapai suatu tujuan tertentu (Hasibuan, 2008:9). Manajemen merupakan proses untuk mencapai tujuan organisasi, baik manajemen sebagai suatu kumpulan pengetahuan yang logis dan sistematis maupun sebagai suatu kreativitas pribadi yang disertai suatu keterampilan.

Sedarmayanti (2010:13-14) menyatakan bahwa MSDM adalah kebijakan dan praktik menentukan aspek manusia atau sumber daya manusia dalam posisi manajemen, termasuk merekrut, menyaring, melatih, memberi penghargaan, dan penilaian.

Siagian (2009:135) menyatakan bahwa kemampuan pemimpin dan seluruh jajaran satuan kerja yang bertanggungjawab untuk mengelola sumber daya manusia dalam suatu organisasi, terlihat antara lain dalam terselenggaranya semua fungsi guna mendukung kegiatan semua komponen organisasi yang bersangkutan.

Robert Heller dalam Wibowo (2010:378) menyatakan bahwa motivasi adalah keinginan untuk bertindak. Sedangkan Robbins dalam Wibowo (2010:378-379) menyatakan motivasi sebagai proses yang menyebabkan intensitas (intensity), arah (direction), dan usaha terus menerus (persistence) individu mencapai tujuan. Motivasi da- 
pat juga diartikan sebagai proses untuk mencoba mempengaruhi orang atau orang-orang yang dipimpinnya agar melakukan pekerjaan yang diinginkan, sesuai dengan tujuan tertentu yang telah ditetapkan lebih dahulu (Uno, 2011:1)

Menurut teori ini faktor-faktor yang mendorong aspek motivasi ialah keberhasilan, Herzberg menyatakan bahwa hubungan individu dengan pekerjaannya merupakan hubungan dasar dan bahwa sikap individu terhadap kerja dapat menentukan, sifat pekerjaan yang menjadi tanggungjawab sesorang, kesempatan meraih kemajuan, dan pertumbuhan. Sofiyanti dan Nurdiansyah (2017) dalam penelitannya mengemukakan bahwa "strongly agree for indicator: encouragement to achieve higher career, high spirit, outstanding ability, opportunity to achieve insight and knowledge, organization concern in gaining insight and knowledge“

Motivasi dapat dipastikan mempengaruhi kinerja, walaupun bukan satu-satunya faktor yang membentuk kinerja. Masukan individual dan konteks pekerjaan merupakan dua faktor kunci yang mempengaruhi motivasi. Peke kerja mempunyai kemampuan, pengetahuan kerja, disposisi dan sifat, emosi, suasana hati, keyakinan dan nilai-nilai pada pekerjaan (Wibowo:, 2010:389-390).

\section{Penilaian kinerja}

Penilaian kinerja yang baik adalah yang dapat memberikan informasi apa yang harus diperbaiki bagi kepentingan individu yang berangkutan karena dengan penilaian yang tepat, dapat mengidentifkasi bagaimanakinerja individu dalam jabatannya, sehingga berdasarkan hasil evaluasi tersbut dapat memberikan feedback lebih lanjut agar pegawai atau kelompok yang bersangkutan dapat menghindari kesalahan dan kegagalan sewaktu mengemban tugas dan tanggungjawab yang diberikan dan dengan penilaian dapat meningkatkan kualitas kerjanya dimasa yang akan datang.

\section{METODE PENELITIAN}

Seperti yang terungkap di dalam identifikasi masalah penelitian, bahwa pokok masalah yang diteliti adalah motivasi $\left(\mathrm{X}_{1}\right)$, kepuasan kerja $\left(\mathrm{X}_{2}\right)$ (sebagai variabel bebas) dan kinerja karyawan (Y) (sebagai variabel terikat).

Teknik sampling yang digunakan dalam penelitian ini adalah probability sampling, yaitu teknik sampling yang memberikan peluang yang sama bagi setiap unsur (anggota) populasi untuk dipilih sebagai sampel. Populasi penelitian yang diteliti adalah karyawan dan karyawati pada Indotech Metal Nusantara Karawang sebanyak 280 orang (PGA Dept., 2011).

Pengumpulan data dilakukan dengan cara penelitian lapangan (field research), melalui penyebaran kuesioner yang terstruktur.

\section{Metode Pengujian Instrumen}

\section{Uji Validitas}

Validitas adalah suatu ukuran yang menunjukkan tingkat-tingkat kevalidan atau kesahihan suatu instrumen. Suatu instrumen yang valid valid atau sahih mempunyai validitas tinggi. Sebaliknya, instrumen yang kurang valid berarti memiliki validitas rendah (Arikunto, 2006:168).

\section{Uji Reliabilitas}

Reliabilitas adalah tingkat kemampuan suatu instrumen penelitian untuk dapat mengukur suatu variabel secara berulangkali dan mampu menghasilkan informasi atau data yang sama atau sedikit sekali bervariasi. Dengan kata lain instrumen tersebut mampu menunjukkan keakuratan, kestabilan dan konsistensi dalam menghasilkan data dari variabel yang diukur (Arikunto, 2006:171).

Uji normalitas digunakan dalam penelitian adalah untuk mengetahui apakah variabel dependen, independen atau keduanya berdistribusi normal, mendekati normal atau tidaknya dengan rumus:

$$
\mathrm{X}^{2}=\Sigma \frac{\mathrm{Oi}^{2}}{E i}-\mathrm{n}
$$

\section{Analisis Deskriftif}

Dalam menggambarkan keadaan motivasi, kepuasan kerja dan kinerja karyawan di PT. Indotech Metal Nusantara Karawang Kabupaten Karawang digunakan rentang skala. Adapun langkah-langkahnya adalah sebagai berikut :

\section{Melihat tabulasi frekuensi}

Hasil Jawaban kuisioner dari responden kemudian dimasukkan ke dalam tabel tabulasi frekuensi 
seperti pada tabel 3.4 dibawah ini.

2. Melihat rentang skala

Menentukan rentang skala dengan menggunakan rumus sebagai berikut:

$$
\begin{aligned}
& R S=\frac{n(m-1)}{m} \\
& R S=\frac{155(5-1)}{5} \\
& R S=124
\end{aligned}
$$

Skala terendah $=$ skor terendah $\mathrm{x}$ jumlah sampel

$$
\begin{aligned}
& =1 \times 155 \\
& =155
\end{aligned}
$$

Skala tertinggi $=$ skor tertinggi $\mathrm{x}$ jumlah sampel

$$
\begin{aligned}
& =5 \times 155 \\
& =775
\end{aligned}
$$

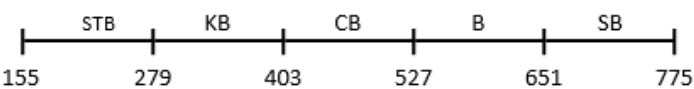

Gambar 1. Rentang Skala

\section{Analisis Korelasi Produk Moment}

Dalam penelitian ini menggunakan Analisis korelasi produk moment (correlation product moment) adalah salah satu pendekatan untuk mengetahui keeratan antara satu variabel dengan variabel lainya, dengan rumus:

$$
\mathrm{r}=\frac{\mathrm{n} \Sigma \mathrm{XY}-\Sigma \mathrm{X} \Sigma \mathrm{Y}}{\sqrt{\left(\mathrm{n} \Sigma \mathrm{x}^{2}-(\Sigma \mathrm{X})^{2}\right)\left(\mathrm{n} \Sigma \mathrm{Y}^{2}-(\Sigma \mathrm{Y})^{2}\right)}}
$$

Sumber : Sugiyono (2010:212)

Dimana:

$\mathrm{r} \quad=$ Koefisien korelasi

$\mathrm{x}=$ Variabel Independen

$\mathrm{n}=$ Jumlah Sampel

$\mathrm{y}=$ Variabel dependen

Dengan ketentuan: bila $r_{s}=+1$ atau mendekati 1, maka korelasi antara kedua variabel dikatakan positif dan sangat kuat sekali bersifat searah. Bila $r_{s}=-1$, Maka korelasi kedua variabel versifat negatif sehingga kenaikan nilai-nilai Y yang sebaliknya. Pengujian signifikan korelasi dapat dihitung dengan uji $t$, dengan perhitungan rumus sebagai berikut:

$$
t=\frac{r \sqrt{n-2}}{\sqrt{1-r^{2}}}
$$

Sumber : Sugiyono (2010: 214)

selanjutnya digunakan distribusi $\mathrm{t}$ dengan $\mathrm{df}=$ $(n-2)$. Kriteria pengujian adalah olah Ho jika $t$ yang dihitung lebih besar dari t tabel jika thitung lebih kecil dari t tabel maka Ho diterima dan $\mathrm{H}_{1}$ ditolak.

\section{Koefisien Determinasi $\left(\mathbf{R}^{2}\right)$}

Analisis koefisien determinasi digunakan untuk menentukan besarnya variasi dari kinerja yang dapat diterangkan oleh variabel kepemimpinan dan motivasi kerja. Koefisien determinasi dilambangkan dengan $\mathrm{R}^{2}$ merupakan proporsi hubungan antara $\mathrm{Y}$ dengan $\mathrm{X}$. Nilai koefisien determinasi adalah diantara 0 (nol) dan 1 (satu). Nilai $\mathrm{R}^{2}$ yang kecil berarti kemampuan variabel-variabel independen dalam menjelaskan variabel dependen amat kecil. Nilai yang mendekati 1 (satu) berarti variabel-variabel independen memberikan hampir semua informasi yang dibutuhkan untuk memprediksi variabel-variabel independen.

\section{HASIL PENELITIAN}

\section{Uji validitas}

Persyaratan minimum agar dapat dianggap valid apabila $r=0,3$. Sehingga apabila korelasi antar item dengan skor total kurang dari 0,3 maka item dalam instrumen tersebut dinyatakan tidak valid. Adapun hasil pengujian mengenai tingkat validitas item kuisioner, dapat dilihat pada Tabel 1.

Berdasarkan hasil analisis Tabel 1, ke- 20 item pertanyaan dari variabel motivasi tersebut mempunyai koefesien korelasi dengan skor totalnya ( $r$ hitung) lebih besar dari pada $r$ kritis yaitu 0,3 yang berarti ke- 20 item pertanyaan kuisioner tersebut valid.

Hasil penelitian lain dari item pertanyaan dari variabel tersebut mempunyai koefesien korelasi dengan skor totalnya ( $\mathrm{r}$ hitung) lebih besar dari pada $r$ kritis yaitu 0,3 yang berarti ke- 15 item pertanyaan kuisioner tersebut valid, serta diperoleh informasi mengenai tingkat validitas item mana saja yang dinyatakan valid dan digunakan untuk penelitian. Hasil pengujian secara lengkap 
dapat dilihat pada lampiran. Dari hasil pengujian tersebut diperoleh bahwa semua item pernyataan dalam kuisioner merupakan item terpilih.

\section{Uji Reliabilitas}

Pengujian dilakukan dengan menggunakan kuisioner yang terdiri dari variabel motivasi (20 item), kepuasan kerja (15 item) dan kinerja karyawan (15 item). Berdasarkan hasil pengujian reliabilitas dengan teknik split half nampak bahwa masing-masing instrument pengukuran adalah reliabel dengan koefisien internal Spearman Brown seperti yang direkomendsikan (Sugiyono) yang menyatakan bahwa batas minimum reliabilitas yang dapat diterima adalah koefisien positif.

Teknik pengujian reliabilitas menggunakan koefisien alpha cronbach dengan taraf nyata 5\% $(0,05)$. Untuk menilai reliabel tidaknya instrumen dilakukan dengan mengkonsultasikan hasil perhitungan alpha cronbach dengan angka tabel r product moment. Untuk melihat tingkat reliabilitas data, SPSS memberikan fasilitas untuk mengukur reliabilitas, jika cronbach Alpha ( $\alpha$ ) $>0,6$ maka reliabilitas pertanyaan bisa diterima (Setiaji, 2004).

Reliabilitas untuk kuisioner masing-masing variabel dapat dapat dilihat pada Tabel 2.

\section{Uji Normalitas}

Uji normalitas digunakan untuk mengetahui apakah suatu data mengikuti sebaran normal atau tidak, untuk mengetahui apakah data tersebut mengikuti sebaran normal dapat dilakukan dengan berbagai metode, diantaranya metode Kolmogorov-Smirnov. Hasil perhitungan data menunjukkan bahwa semua variabel mengikuti distribusi normal dengan p-value $>\alpha$ (Sudjana, 2005: 273), yang dijelaskan pada Tabel 3.

Tabel 1

Hasil Validitas Item Variabel Motivasi $\left(\mathrm{X}_{1}\right)$

\begin{tabular}{|c|c|c|c|}
\hline Nomor item & r hitung & r kritis & Kriteria \\
\hline$X_{1-1}$ & 0,606 & 0,3 & Valid \\
\hline$X_{1} \_2$ & 0,439 & 0,3 & Valid \\
\hline$X_{1} \_3$ & 0,362 & 0,3 & Valid \\
\hline$X_{1-4}$ & 0,714 & 0,3 & Valid \\
\hline$X_{1-5}$ & 0,397 & 0,3 & Valid \\
\hline$X_{1-6}$ & 0,485 & 0,3 & Valid \\
\hline$X_{1-} 7$ & 0,631 & 0,3 & Valid \\
\hline$X_{1} \_8$ & 0,643 & 0,3 & Valid \\
\hline $\mathrm{X}_{1-} 9$ & 0,570 & 0,3 & Valid \\
\hline$X_{1-10}$ & 0,613 & 0,3 & Valid \\
\hline$X_{1-11}$ & 0,576 & 0,3 & Valid \\
\hline$X_{1-12}$ & 0,588 & 0,3 & Valid \\
\hline$X_{1-13}$ & 0,676 & 0,3 & Valid \\
\hline$X_{1-14}$ & 0,481 & 0,3 & Valid \\
\hline$X_{1-15}$ & 0,522 & 0,3 & Valid \\
\hline$X_{1} \_16$ & 0,625 & 0,3 & Valid \\
\hline$X_{1-17}$ & 0,653 & 0,3 & Valid \\
\hline$X_{1-18}$ & 0,643 & 0,3 & Valid \\
\hline$X_{1-19}$ & 0,702 & 0,3 & Valid \\
\hline$x_{1-20}$ & 0,382 & 0,3 & Valid \\
\hline
\end{tabular}

Sumber : Hasil pengolahan data, 2012

Tabel 2

Reliabilitas

\begin{tabular}{lccl}
\hline Variabel & $\mathbf{R}_{\text {Hitung }}$ & $\mathbf{R}_{\text {Kritis }}$ & Kriteria \\
\hline Motivasi $\left(\mathrm{X}_{1}\right)$ & 0,915 & 0,6 & Reliabel \\
Kepuasan kerja $\left(\mathrm{X}_{2}\right)$ & 0,783 & 0,6 & Reliabel \\
Kinerja Pegawai $(\mathrm{Y})$ & 0,898 & 0,6 & Reliabel \\
\hline
\end{tabular}

Sumber : Hasil pengolahan data, 2012 
Tabel 3 menunjukkan bahwa variabel yang mengikuti sebaran data normal adalah variabel kepuasan kerja karena nilai p-value $>0,05$. Sedangkan untuk varabel motivasi dan kinerja karyawan tidak mengikuti sebaran data normal.

\section{Rekapitulasi variabel Motivasi}

Berdasarkan pendapat responden dari masingmasing item selanjutnya dibuat rekapitulasi variabel motivasi. Variabel ini berada dalam kriteria baik seperti terlihat pada Gambar 2 di bawah ini:

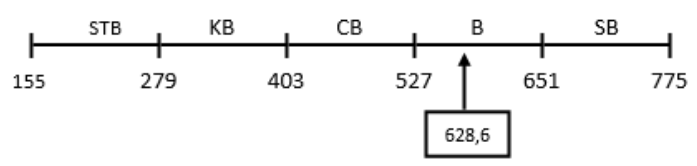

Gambar 2. Rentang Skala Motivasi $\left(\mathrm{X}_{1}\right)$

Berdasarkan tabel di atas dapat diketahui bahwa motivasi karyawan di PT Indotech Metal Nusantara berada dalam kondisi baik dengan skor total 628,6. Hal ini menunjukkan motivasi karyawan cukup tinggi di dalam melakukan pekerjaannya.

\section{Rekapitulasi variabel Kepuasan kerja}

Berdasarkan pendapat responden dari masingmasing item selanjutnya dibuat rekapitulasi variabel kepuasan kerja seperti yang ditampilkan variabel ini berada dalam kriteria baik seperti terlihat pada Gambar 3 di bawah ini :

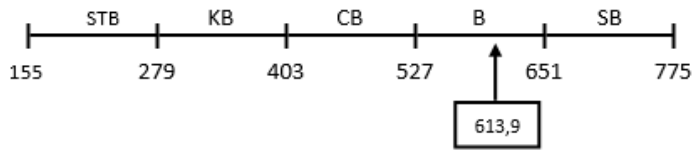

Gambar 3. Rentang Skala Kepuasan Kerja $\left(\mathrm{X}_{2}\right)$

Berdasarkan Gambar 3 di atas dapat diketahui bahwa kepuasan kerja karyawan di PT Indotech Metal Nusantara berada dalam kondisi baik dengan skor total 613,9. Hal ini menunjukkan kepuasan kerja karyawan sudah cukup tinggi, artinya karyawan sudah merasa puas dengan pekerjaan dan apa yang telah diterimanya dari perusahaan.

\section{Kinerja Karyawan PT Indotech Metal Nusantara}

Gambaran mengenai kinerja karyawan yang ada pada PT Indotech Metal Nusantara dideskripsikan tentang pendapat responden mengenai
: pimpinan merasa puas dengan pekerjaan yang telah saya laksanakan, yakni sebanyak 23,9\% menyatakan sangat setuju, 64,5\% menyatakan setuju, 9,0\% menyatakan kurang setuju, dan $2,6 \%$ menyatakan tidak setuju dengan skor total 635. Skor tersebut berada pada rentang skala baik. Hal tersebut menunjukkan kinerja karyawan PT Indotech Metal Nusantara dari aspek pimpinan merasa puas dengan pekerjaan yang telah dilaksanakan oleh karyawan, sebagian besar karyawan telah memiliki kinerja yang tinggi. Karyawan telah melakukan pekerjaan yang bermutu dan memberikan kepuasan kepada pimpinan.

Selain itu dapat dideskripsikan tentang pendapat responden mengenai : rekan sejawat merasa puas dengan pelayanan yang saya berikan, yakni sebanyak 21,3\% menyatakan sangat setuju, 59,4 $\%$ setuju, dan 19,3\% kurang setuju dengan skor total 623. Skor tersebut berada pada rentang skala baik. Hal tersebut menunjukkan kinerja karyawan PT Indotech Metal Nusantara dari aspek rekan sejawat merasa puas dengan pelayanan yang di berikan, sebagian besar karyawan telah melakukan pelayanan yang bermutu dan memberikan kepuasan kepada rekan sejawat.

\section{Rekapitulasi variabel Kinerja}

Berdasarkan pendapat responden dari masingmasing item selanjutnya dibuat rekapitulasi variabel kinerja karyawan seperti variabel ini berada dalam kriteria baik seperti terlihat pada Gambar 4 di bawah ini:

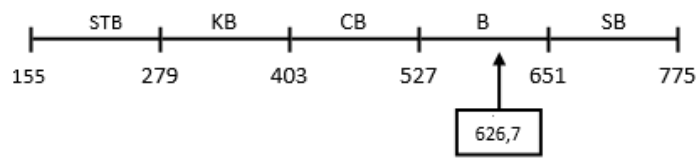

Gambar 4. Rentang Skala Kinerja Karyawan (Y)

\section{Besaran Hubungan Antara Variabel Bebas}

Tabel 4 menunjukkan bahwa hasil perhitungan korelasi dengan model 2-tailed atau dua sisi diperoleh hubungan antara variabel motivasi dengan kepuasan kerja sebesar 0,205.

\section{Koefisien Jalur Motivasi $\left(\mathrm{X}_{1}\right)$ terhadap \\ Kinerja Karyawan (Y)}

Pengaruh secara parsial variabel $\mathrm{X}_{1}$ yaitu motivasi terhadap variabel $\mathrm{Y}$ yaitu kinerja karyawan 
Tabel 3

Uji Normalitas Instrumen

\begin{tabular}{lccc}
\hline & \multicolumn{2}{c}{ Kolmogorov-Smirnov } & Kesimpulan \\
& p-value & $\boldsymbol{a}$ & \\
\hline Motivasi $\left(\mathrm{X}_{1}\right)$ & 0,005 & & Dist. Tidak Normal \\
Kepuasan Kerja $\left(\mathrm{X}_{2}\right)$ & 0,247 & 0,05 & Dist. Normal \\
Kinerja Karyawan $(\mathrm{Y})$ & 0,006 & & Dist. Tidak Normal \\
\hline
\end{tabular}

Sumber : Hasil Pengolahan Data, 2012

Tabel 4

Korelasi Bi-Variate

\begin{tabular}{llll}
\hline & & Motivasi & Kepuasan kerja \\
\hline Motivasi & Pearson Correlation & 1 &, $205\left(^{\star *}\right)$ \\
& Sig. (2-tailed) & &, 010 \\
& $\mathrm{~N}$ & 155 & 155 \\
\hline Kepuasan kerja & Pearson Correlation &, $205\left(^{* *}\right)$ & 1 \\
& Sig. (2-tailed) &, 010 & \\
& $\mathrm{~N}$ & 155 & 152 \\
\hline
\end{tabular}

** Correlation is significant at the 0.01 level (2-tailed).

menggunakan software SPSS 15 menunjukkan pengaruh langsung variabel $\mathrm{X}_{1}$ terhadap $\mathrm{Y}$ yaitu sebesar 0,559 sehingga diperoleh persamaan $\mathrm{Y}=$ $0,559 \mathrm{X}_{1}$

\section{Koefisien Jalur Kepuasan Kerja $\left(\mathrm{X}_{2}\right)$ terhadap Kinerja Karyawan (Y)}

Pengaruh secara parsial variabel $\mathrm{X}_{2}$ yaitu kepuasan kerja terhadap variabel Y yaitu kinerja karyawan menggunakan software SPSS 15 menunjukkan pengaruh langsung variabel $\mathrm{X}_{2}$ terhadap $\mathrm{Y}$ yaitu sebesar 0,267 sehingga diperoleh persamaan $\mathrm{Y}=0,267 \mathrm{X}_{2}$. Hal ini menggambarkan persamaan jalur, sehingga dapat diperoleh persamaan jalur sebagai berikut:

$$
Y=0,559 X_{1}+0,267 X_{2}+\mathcal{E}
$$

Dimana:

$\mathrm{Y}=$ Kinerja Karyawan

$\mathrm{X}_{1}=$ Motivasi

$\mathrm{X}_{2}=$ Kepuasan kerja

Dari persamaan di atas dapat diartikan bahwa adanya hubungan asosiatif antara motivasi dengan kinerja karyawan besarannya sebesar 0,559 $\left(\rho_{\mathrm{YX} 1}\right)$. Artinya bahwa setiap peningkatan motivasi sebesar 1 satuan, maka akan meningkatkan kinerja karyawan sebesar 0,559 satuan. Serta danya hubungan asosiatif antara kepuasan kerja dengan kinerja karyawan besarannya sebesar 0,267 ( $\left.\rho_{\mathrm{YX} 2}\right)$. Artinya setiap peningkatan kepuasan kerja sebesar 1 satuan, maka akan meningkatkan kinerja karyawan sebesar 0,267 satuan. Nilai koefisien jalur variabel motivasi lebih besar dibandingkan koefisien jalur kepuasan kerja, artinya motivasi lebih menentukan (pengaruh) dibandingkan kepuasan kerja baik secara langsung maupun tidak langsung terhadap kinerja karyawan.

\section{Pengaruh Bersamaan Variabel X Terhadap Variabel Y.}

Pengaruh langsung dan tidak langsung secara simultan dari variabel motivasi $\left(\mathrm{X}_{1}\right)$ dan kepuasan kerja $\left(\mathrm{X}_{2}\right)$ terhadap kinerja karyawan $(\mathrm{Y})$ variabel motivasi mempunyai pengaruh langsung terhadap variabel kinerja karyawan sebesar 31,25\%, pengaruh tidak langsung melalui hubungannya dengan variabel kepuasan kerja sebesar 3,06\%. Sedangkan variabel kepuasan kerja mempunyai pengaruh langsung terhadap variabel kinerja karyawan sebesar $7,13 \%$, pengaruh tidak langsung melalui hubungannya dengan variabel kepuasan kerja sebesar 3,06\%. Total pengaruh dari variabel bebas : motivasi $\left(\mathrm{X}_{1}\right)$ dan kepuasan kerja $\left(\mathrm{X}_{2}\right)$ terhadap kinerja karyawan (Y) dinyatakan oleh besaran koefisien determinasi $\left(\mathrm{R}_{\mathrm{YX}}\right)^{2}$ sebesar 44,50\%. Efek dari faktor lain terhadap kinerja karyawan ditunjukkan oleh nilai $\rho y \varepsilon=0,555$ atau sebesar $55,50 \%$ 


\section{REFERENSI}

Effendi, Onong Uchjana. 1995. Psikologi Manajemen. Bandung: Alumni.

Gusmana, Agus. 2008. Pengaruh Budaya Organisasi, Disiplin Kerja dan Motivasi Kerja terhadap Kinerja Aparat Kecamatan Batujajar Kabupaten Bandung Barat. Tesis. Program Pascasarjana Magister Manajemen. Sekolah Tinggi Ilmu Ekonomi Pasundan.

Harris, O., Jeff, Jr. 2000. managing People At Work, Consept and Casis in Interpersonal Behavior. USA: John Willey And Sons inc, New York.

Jones, Garet, R. 2004. Organization Theory, Design, and Change. Singapore: Pte.Ltd.Indian Branch.

Kuswanda, Uus. 2006. Pengaruh Kemampuan Kerja, Motivasi Kerja dan Disiplin Kerja terhadap Kinerja Pegawai Biro Dekonsentrasi dan Tugas Perbantuan SETDA Provinsi Jawa Barat. Tesis. Program Pascasarjana Magister Manajemen. Sekolah Tinggi Ilmu Ekonomi Pasundan.

Locke, Edwin. A. \& Assosiates. 1997. Esensi Kepemimpinan. Jakarta: Mitra Utama.

Mangkunegara, A.P. 2001. Manajemen Sumber daya Manusia Perusahaan. (cetakan ke-3). Bandung: PT. Remaja Rosda Karya Offset.

Mas'ud, Fuad. 2004. Survey Diagnosis Organizational: Konsep dan Aplikasi. Semarang: Badan Penerbit Universitas Dipenogoro.

Miftah, Toha. 2001. Kepemimpinan dalam Manajemen: Suatu Pendekatan Perilaku. Jakarta : Rajawali Press.

Minner, Jhon, B. 1992. Organizational Behavior, Performance Productivity. Fith edition. New York: Random House, inc.

Mirza. 2008. Hubungan Budaya Organisasi, Dukungan Organisasi dan Motivasi Kerja dengan Kinerja Karyawan PT BRI Tbk Yogyakarta. Tesis. Program Pascasarjana Program Studi Psikologi. Universitas Gadjah Mada.

Mulyadi. 2010. Pengaruh Iklim Kerja dan Motivasi Kerja terhadap Komitmen serta Implikasinya pada Kinerja Pegawai di Lingkungan Sekretariat Daerah Kabupaten Bandung Barat. Tesis. Program Pascasarjana Magister Manajemen. Sekolah Tinggi Ilmu Ekonomi Pasundan.

Nawawi, H. 2003. Metode Penelitian Bidang Sosial. Yogyakarta: Gadjah Mada University Press.

Sofiyanti, N. dan Nurdiansyah, D.H. 2017. Mutation and Career Development to the Performance of Structural Officials (Case Study of Karawang Government). E-Mabis Jurnal. 18(2), 7-14.

Organ, W.D. 1991. The Applied Psychologi Of Work Behavior. Vote Edition. Richard D Irwin, inc.

Orpen. 2001. Interactive Effect Of Work Motivation And Personal Control On Employee Job Performance And Satisfaction. Jurnal off Sosila Psychologi. 134, 6, p 855-856. 
Riduwan dan Kuncoro, Engkos Achmad. 2008. Cara Menggunakan dan Memaknai Analisis Jalur (Path Analysis). Cetakan Kedua. Bandung: Alfabeta.

Siagian, Sondang. 1999. Manajemen Sumber Daya Manusia. Jakarta:Bumi Aksara.

Soe, M.G., et.al. 2004. The Role Of Affective Experience In Work Motivation. Academy of Management Review 29, (3), 423-439.

Sugiyono. 2010. Metode Penelitian Administrasi. Bandung: CV. Alfabeta.

Sutarto. 2000. Dasar-Dasar Kepemimpinan Administrasi. Yogyakarta: Gadjah Mada Universitiy Press.

Suradinata, Ermaya. 1997. Pemimpin dan Kepemimpinan Pemerintah. Jakarta: PT. Gramedia.

Uno, H.B. 2007. Teori Motivasi dan Pengukuran. Jakarta: Bumi Aksara.

Wahdjosumidjo. 1994. Kepemimpinan dan Motivasi. Jakarta. Ghalia Indonesia.

Winardi. 2000. Organisasi Perkantoran dan Motivasi. Bandung:Alumni. 
